\title{
Mobile-Assisted Writing Instruction: Affordances, Challenges, and Future Directions
}

\author{
https://doi.org/10.3991/ijim.v15i10.21519 \\ Xiaodong Zhang \\ Beijing Foreign Studies University, Beijing, China \\ zxdman588@gmail.com
}

\begin{abstract}
Mobile-assisted language learning (MALL) is widely adopted worldwide. One related issue under discussion is how to effectively harness mobile devices to help English writers. This discussion paper first unpacks writing as a meaning-making process from the perspective of systemic functional linguistics. It then summarizes the major MALL-based studies on writing instruction, including the affordances and challenges of mobile-assisted writing instruction. The paper is followed by discussing pedagogical tips for teachers interested in using MALL and SFL to improve students' English writing construction across different educational contexts (e.g., at the tertiary and pretertiary level).
\end{abstract}

Keywords-Mobile learning; writing instruction; teaching methods; innovation; meaning-making

\section{Introduction}

With the assistance of wireless networks, the use of mobile devices, such as iPhones and tablets, is widespread in educational settings [1], [2], [3], [4]. Mobileassisted language learning (MALL) generally refers to language learners' use of portable devices (e.g., mobile phones, laptops) for learning and practicing knowledge, either through using materials or interacting with teachers or peer learners in and out of class anytime and anywhere [5]. MALL is ubiquitous among language learners, especially college students who have more freedom to use portable devices [6]. Compared to traditional learning, MALL and its accompanying resources (e.g., web and applications) have been found to foster students' engagement with learning, such as providing collaborative spaces and conveniently accessible information [6]. Nevertheless, $\mathrm{Xu}$, Banerjee, Ramirez, Zhu, and Wijekumar reported that MALL is primarily used to teach vocabulary with little attention paid to writing, despite the potential to improve instruction through mobile devices [7]. Besides, while "it would not be very realistic to expect learners to write or edit a paper on mobile devices" [6, p.138], it would be helpful to rely on them to deliver information and improve students' literacy, given the popularity of mobile devices in this digital world and their convenience as a medium for knowledge building. 
In particular, student writers often misuse language during their written expression, such as incorporating spoken expressions in their writing [8]. This means that before utilizing MALL, writing teachers must first have adequate language knowledge to understand the intricacies of writing composition, especially on how to teach students to write meaningfully since meaningful writing is what is valued [9]. In this sense, writing teachers need to know the close relationship between language and context (i.e., how particular language resources are used in response to diverse contexts-a meaning-making process) [10]. Unfortunately, among the limited research on MALL for writing instruction, grammatical accuracy is emphasized more than meaningful and effective writing, such as [11] and [12]. This may be due to constrained teacher education for preservice and in-service language teachers, blurring students' vision in understanding the underlying nature of effective writing [13]. There is an imperative need for writing teachers to receive effective teacher education and deliver practical knowledge when using the technological functions of mobile devices to help student writers understand language effectively and enable them to navigate written discourse autonomously [7].

To facilitate the design and use of MALL and contribute to the literature on writing instruction, this paper first unpacks writing as a meaning-making process from the perspective of systemic functional linguistics. It then summarizes relevant research and demonstrates the potential of incorporating meaning-making knowledge into mobile-assisted writing instruction. It is followed by pedagogical tips for writing teachers who intends to integrate MALL and SFL inside and outside their classroom.

\section{Systemic Functional Linguistics as a Potentially Helpful Framework for Mobile-Assisted Writing Instruction}

Halliday's systemic functional linguistics (SFL) emphasizes that effective writing is more than language accuracy [14]. It highlights the dynamic mechanism of effective writing while making transparent what constitutes effective writing. In particular, SFL, at a higher level, points out that written communication is presented through different generic stages to achieve a social purpose (e.g., to narrate). For instance, when narrating, a story starts with orientation and ends with code, see also [15] for different generic stages). SFL then provides multiple constructs to unravel the mystery of writing through a crystal explanation of the interactions between meaning (i.e., content) and language (i.e., using vocabulary and grammar appropriately) in different contexts.

In particular, the contextual variables include what is talked about, at whom the communication is targeted, and how information is conveyed. Echoing the three contextual variables, written communication has three dimensions of content (i.e., meanings) to be expressed. The three meanings are, respectively, ideational meaning (i.e., the gist of thoughts to be delivered, including the logical relationships between the thoughts), interpersonal meaning (i.e., the content concerning authorial stances and the formality of the content), and textual meaning (i.e., the content about how a large stretch of sentences or utterances is connected). 
SFL has its codes, in addition to structural accuracy, which explains how to use context-specific linguistic choices to express the three dimensions of content; see [14] for details. With these codes, some language features beyond grammatical accuracy have been identified in valued writing. Take informative writing, for example. The generic stage may be an introduction, body paragraphs, and conclusion. In terms of ideational meaning, codes, such as participant (a label for understanding nouns and noun phrases in sentences) and logical connectors (labels for revealing logical relationships), show that ideational meaning prefers topic-related nouns or noun phrases and the explicit use of logical connectors in informative writing rather than casual use of language as in spoken English. Expressions at the interpersonal level can be unpacked through codes such as attitude (a label for emotional words) and engagement (a label for words meaning certainty or the source of information). These codes show that interpersonal meaning prefers an implicit use of evaluative words and a calibrated use of modal verbs concerning the strength of evidence in informative writing [13]. The codes for understanding textual meaning include cohesive devices (i.e., labels for conjunction words, synonyms, antonyms, and repetition) and theme-rheme patterns (a label for the arrangement of starting points of sentences). It shows that in academic writing, textual meaning prefers cohesive devices or diverse theme-rheme patterns (e.g., repeating starting information) to connect a large stretch of texts and achieve unity in the text [10], [16]. In all, SFL-based knowledge seems valuable for meeting students' linguistic needs using mobile devices (e.g., material development and delivery), enhancing their knowledge of writing beyond language accuracy.

Relevant research, especially in the traditional classroom, has demonstrated the usefulness of SFL to help students power through challenges in the writing classrooms following the reading to learn cycle (i.e., reading sample texts and then guiding students in understanding meaning-making and constructing their writing) [13], [17], [18], [19]. For example, Moore, Schleppegrel, and Palincsar focused on elementary English-as-a-second-language (ESL) students in the US who were exposed to the teaching of narratives from a functional linguistic perspective [20]. Over two years, the students were able to identify the interrelationships between linguistic resources and meanings in sample narrative texts, such as the identification of processes at the ideational level and appraisal resources at the interpersonal level. They also practiced their writing accordingly. Yasuda's research also showed the value of teaching writing from the perspective of SFL in an English as a foreign language (EFL) context at the college level [19]. In the study, Japanese EFL college students majoring in biology demonstrated their writing development when summarizing information. For example, following exposure, students used grammatical metaphors (e.g., nominal groups) and reporting verbs, meeting the demands of summary writing in their field. Zhang also showed how SFL benefited Chinese EFL students' argumentative writing [13]. In the study, the college students also transcended themselves, switching the focus from structural accuracy to meaning-making (e.g., students' use of modal verbs and citations at the interpersonal level and their use of conjunctions or synonymy in creating cohesion at the textual level). In all, these studies demonstrated the usefulness of SFL to enhance student writers' knowledge of writing. 


\section{Significant Findings on MALL-Based Writing Instruction}

Research on writing instruction and composition through mobile devices has emerged within the past ten years, especially at the college level. The research context in colleges may be due to the greater freedom afforded to college students to use mobile devices in and out of class [6]. This line of research can be categorized into three main streams, although there are some overlaps.

One is on mobile devices in conveying knowledge of writing at the linguistic level, especially grammar knowledge, whereby delivery is achieved through mobile applications. For example, Li and Hegelheimer investigated MALL-based writing among ESL learners in a college writing course in the United States (US) [6]. Using a grammar application (i.e., Grammar Clinic), students were guided to learn grammar knowledge related to their academic writing (e.g., avoiding run-on sentences and using the correct verb tense). Their study showed that the students generally liked the mobile application, used it after class on their own (e.g., on the bus) to improve their grammar knowledge, and edited their essays accordingly. With the same focus on grammar, writing teachers also used mobile devices and created peer-collaborative environments for student writers [6]. Andujar focused on how short message application-based communications created a collaborative space for peer writers and reported how mobile-based learning impacted students' linguistic accuracy [21]. In the sixmonth study conducted among third-year college students from a university in Spain, Andujar found that in comparison with the control group, the ESL students' linguistic errors improved through mobile-based interactions, such as lexical errors, grammatical errors, and mechanical errors (e.g., spelling and punctuation). This study also resonates with the latest review study conducted by Kukulska-Hulme and Viberg [22], who examined publications from 2012-2016 and concluded that mobile devices help create collaborative learning contexts and support students' academic development at the linguistic level.

Another line of research focused more on the technological functions of mobile applications concerning students' writing engagement. Al-Naibi, Al-Jabri., and AlKalbani investigated a mobile application (i.e., Edmodo, an educational website for users to collaborate and solve problems) and its impact part-time English language learners from the Arab Open University [11]. The application included uploading, saving, and sharing documents or videos and providing online feedback on the part of the teachers. It also included "quiz, poll, assignment, grade book and other tools that assist teachers in assessing students" [11, p. 130]. Besides, it had an autocorrect feature for grammar errors so students could focus on writing paragraphs. The students were instructed about the structure of writing and identified sentence structures in texts through quizzes (e.g., topic sentences) in the application, based on 10 hours of teaching over 15 weeks. The students took pictures of how they brainstormed and uploaded these to the application. They also wrote and edited their writing within the application. Nevertheless, they also complained about the difficulties involved with using mobile phones, such as mobile phones' limited storage and using the technology itself. Overall, students reported that mobile-based learning was valuable, such as correcting grammar, spelling, and other relevant mobile-based activities. Sessions, 
Kang, and Womack's nine-week study focused on fifth-grade students and their iPad applications in the US [23]; their findings also echoed Al-Naibi et al.'s research [11]. Thirty students were involved in the study, of which 15 were in the control group, and the other 15 were in a treatment group. They found that students with iPads could visualize their thoughts and better sequence them logically during their narrative writing. They also felt more motivated to write and were willing to cooperate than the control group, who just received the same teacher's instruction.

The third research line primarily focused on a mobile device-based peer learning environment, especially through short message service (SMS), and its effect on student writers. In the latest study, Kayaoğlu and Çetinkaya conducted a seven-week study among 26 English students from a Turkish university [24]. Through SMS, the instructor sent the students one sentence as a starter. Working in groups, the students followed a predetermined order, adding to the sentence and forwarding it to the next group. Each group was offered one more chance to look at their sentence before the last student sent the final version to the instructor. The instructor also offered face-toface feedback on language form and the use of conjunction words through video conferencing. The students reported that they could choose a convenient time to respond, practiced the grammar learned and the new vocabulary acquired from their classmates, and gained ideas through collaborative work within the group. Some challenges were also reported in the study, such as storage capacity limitations and difficulties in writing on the screen.

What particularly merits attention is that the knowledge of writing delivered through mobile devices is still limited to language form at the linguistic level, without incorporating a meaning-making process - the valued mechanism of writing [10]. This may be due to under-resourced teacher education; indeed, teachers and their pedagogical knowledge influence their technological practices [13]. This suggests the importance of promoting MALL beyond grammar at the linguistic level while including its technological affordance to provide comprehensive assistance and implementing relevant teacher education. Indeed, $\mathrm{Xu}$ et al.'s review studies on writing instruction concerning MALL, spanning 2000 to 2017, revealed that relevant research showed the positive role of technology in facilitating students' writing, such as providing collaborative environments through a wiki, online corrections, and feedback from peers and teachers on, for example, grammar [7], but these studies seemed to downplay the importance of meaning construction beyond grammar within the demands of genres [7]. Besides, in Xu et al.'s review on collaborative (e.g., blogging) and noncollaborative (e.g., the delivery of podcasts) writing, they also concluded that noncollaborative technologies seem to have a more significant impact on writing than collaborative technology applications [7, p. 155] because of the cognitive load needed to process information from the group and transfer it to their writing. This suggests the favorable adoption of mobile-based content delivery to enhance students' in-class learning and facilitate their knowledge of writing and practice, in terms of both language (e.g., grammar) and meaning (idea developing and supporting) [25].

Existing mobile-based research, informed by SFL, such as [26], provides insights into advancing MALL. Among a few studies, Noriega demonstrated how SFLinformed genre pedagogy in tandem with mobile technology impacted students' 
meaningful writing [26]. Through an eight-week track of one college student from Colombia, the study found that podcasts on genre delivered through mobile devices facilitated the student's narrative texts production. For example, in addition to improving her grammar, the student found the mobile-based podcasts helpful for producing and revising her texts, such as the generic structure of the narrative texts and cohesive devices. The study illuminates the practical value of integrating SFL and mobile technology. Nevertheless, this type of research is scarce and merely involves generic structure and cohesive devices, making a more comprehensive tandem between SFL and MALL necessary and promising.

Overall, the value of mobile devices for student writers is obvious, such as creating multimedia-based learning without geographic constraints. However, the instructional and learning content delivered via MALL is limited to grammar, which needs further enhancement. SFL's perspective on writing shows the different layers that constitute effective communication, making it useful for students' writing development when synthesizing valuable features of mobile devices for writing instruction.

\section{An Instructional Model Based on MALL and SFL}

A scarcity of studies on the comprehensive integration of MALL-SFL may be due to a lack of teacher education [27], [28], pointing to the need to help teachers conjugate the two constructs and assist them with its implementation. This section delineates how to integrate MALL and SFL inside and outside the writing classroom.

\subsection{Teachers' embrace of technology}

The convenience of technology is sometimes in conflict with teachers' practices. Some teachers may be unwilling to use technology or feel uncomfortable with it [29], [30]. However, in this digitalized world, students' repertoire of technology is increasingly essential as a critical competency in their study and future work, and teachers play a vital role in shaping their literacy learning and production [31] [32]. For teachers, "significant questions arise and further research is needed to address matters such as access to technology as well as teacher training that would enable them to feel fully confident in using tools that support the instruction of writing" [30, p. 49]. To enhance their use of technology and related self-efficacy, teachers need to change their conceptualization and wire themselves with a technological mindset [27], [32], [33].

This may include the following four recursive components. One is brainstorming with teachers to galvanize their interest [34]. Teachers should first be encouraged to become familiar with different functions of mobile technology, such as diverse applications that can be used for writing (e.g., Edmodo), in addition to web resources, see [30], [32] for other applications. This can be achieved by inviting experts in mobile technology and introducing the latest applications. Doing so may pique teachers' interest. The second is to encourage teachers to design and implement technologybased instruction in a supported environment [35]. Teachers could be encouraged to understand students' needs, where they may understand students' positive stance to- 
ward the use of technology, such as mobile use. Teachers can then assist with tentatively enacting applications, particularly the most accessible ones such as podcasts, and ask for students' feedback. The third is the teachers' reflections and modification making (self or external) [33], [36]. This involves the teachers identifying the technological hindrances encountered during implementation and solving them independently or through external assistance. Furthermore, teachers may also encounter the challenges, such as what content to deliver to their students, which will be addressed in the following two sub-sections. Fourth is changing teaching beliefs and practices [27]. In this recursive dynamic, teachers may understand the usefulness of mobile technology and become gradually more confident in using it. They may also update their teaching beliefs and become willing to enact new practices, such as using mobile devices in their classrooms.

\subsection{What teachers should know}

Materials are the primary sources for students' learning and gaining knowledge [13]. Therefore, the first thing is to sift through and curate materials, including videos, web-related resources, and portable document formats (PDF), which relate to and supplement their classroom teaching.

Regarding MALL-based writing instruction, to complement the accuracy-based practices via mobile devices, teachers need to gain a meaning-making perspective on writing before organizing, implementing, and delivering resources. However, in this aspect, teachers generally appear to have limited knowledge [37] [38]. To this end, SFL experts can be invited to assist teachers. The intention is to understand different varieties of language use across contexts used for effective communication. In particular, learning and digesting this could be complex and takes time [20]. To alleviate the cognitive burden and engage teachers authentically rather than mechanically in using the toolkit from SFL, SFL experts could follow good-enough principles (i.e., choosing the most relevant content and make it accessible to writing teachers), see [39] and expose teachers to reflection-based practices [33]. That is, SFL experts could teach features that are most prominent in different modes or genres of discourse, use plain language in unpacking the language theory, see also [8], and help teachers reflect upon the theory based on their actual teaching (e.g., model teaching among colleagues or their own in-class teaching).

Meanwhile, application designers are encouraged to collaborate with SFL experts in the process of offering teacher education. By working together, they can convey elements that include SFL and technological conveniences (e.g., relevant applications such as Edmodo), which are pertinent to effective written communication.

Take an informative essay as an example. When teaching this, SFL experts could first help teachers contextualize writing beyond the grammatical level, using the reading to learn approach. Teachers are also expected to follow these procedures in their future classrooms. Below are the sample procedures, based on a freely accessible sample of informative writing (https://ngl.cengage.com/assets/downloads /greatwi_pro0000000335/gw5_unit6.pdf; pp.139-141). 
Contextual variables: Field (i.e., the influence of weather on history), tenor (i.e., an information-broadcasting tone), and mode (in formal written language) are taught.

Meaning representation in this text: In terms of ideational meaning, labels, such as participants, and processes, and logical connectors can be highlighted to unveil the use of nouns, verbs, and conjunction words, respectively. When illustrating the influence of weather, the author used effects, caused and led to presenting an event involving causes and effects, among similar semantic representations throughout the text. In terms of interpersonal meaning, labels such as attitude and engagement can be highlighted. The label of attitude can help sensitize teachers regarding the implicit use of authorial emotions. One example is the use of simple facts when talking about how Napoleon overlooked the cold weather. This can help teachers understand that while an informative essay is about conveying information in an objective tone, it can still convey authorial stances, although in implicit ways (i.e., through the word overlook). Besides, the label of engagement can guide teachers in understanding the use of citations to enhance the reliability of evidence, and the use of mitigated expressions to construct effective claims, such as modal verbs (e.g., might) and other lexical categories, including verb phrases (e.g., appear, be likely). The labels of cohesive ties and themes can help teachers understand the relationship between sentences, such as transitional words (e.g., however, nonetheless), and the constant use of semantically related words to start sentences (e.g., repetition of the word Napoleon when describing his failure in Russia). By exposing them to the teaching mentioned above, pre-or inservice teachers may understand SFL and its application in deconstructing and constructing texts.

\subsection{Teaching via the conjugated use of mobile devices and SFL}

Teachers unpack writing, solidifying or engaging students' understanding of what constitutes effective writing from the perspective of SFL and MALL. This approach may include the following dimensions.

Deliver supplementary resources through mobile devices: This may include multimedia resources from an SFL-based perspective (see Appendix for sample links). Desirably, the resources should be short in length so teachers can use mobile devices to help students learn anywhere, for example, during transportation [6]. By doing so, teachers can enhance students' understanding of SFL-based materials used in class or clarify their confusion.

Independent work on the part of students: Following model learning, students could be guided in finishing similar tasks, identifying the linguistic resources that are used. Teachers could consider applications (e.g., Edmodo) that have forums and help users communicate and evaluate each other's progress [30]. Other similar applications can also be used to create a learning space for students, such as wikis. The task and evaluation can be based on their text understanding (i.e., ideational, interpersonal, and textual meaning) concerning the linguistic resources in different contexts.

Mobile-based mediation of students' learning: Video conferencing through chat tools (e.g., Wechat, a multimedia chatting tool developed by a Chinese company) can be used to provide feedback and clarify confusion among students through texts or 
voice messages. Another mobile application that can be used in this case is Zoom (an application for video conferencing developed by a US company), a newly popular tool for conferring while documents under discussion are shared and seen by the participants of the video conference. Teachers could provide implicit feedback in line with a meaning-making perspective (e.g., the relationship between linguistic choices and three meanings for different writing genres). The comments could be: "What do you think of the cohesion between the text chunks? Do you notice authorial stance in the texts?" It is worth noting that writing teachers could have students think about or correct writing issues beforehand by providing them with written feedback on their work via paper or Microsoft Word since writing comments directly on mobile devices may be constrained by space limitations [6]. The pedagogical intention is to help students develop their meaning-making awareness and ultimately self-regulate their essays. Indeed, the focus of mobile-based technology is not on the fancy use of technology itself. Instead, it is intended to foster students' learning engagement, autonomy, and lifelong learning [40], [41].

\subsection{Continuous development in the institution}

Educational policies also condition teachers' enactment of teaching, which may hinder their development. As Aguirre-Muñoz et al. noted, language teachers' alignment with SFL-based training receded in schools where accuracy is emphasized [42]. This means that teachers may need to gain administrative support by showing administrators the empirical effects of SFL in writing classrooms and the content delivery through technology [41], [43].

More importantly, teacher development is not one for all. They need to rely on themselves and constantly reflect on their teaching and make appropriate adaptions that ensure all parties' interests (e.g., students' high stakes tests) [43]. In particular, students in local contexts vary with their preferences, learning styles, cognitive preferences, and different mobile devices [44], [45]. To make both technology and knowledge of writing accessible to students, teachers may need to rely on themselves and constantly reflect on engaging students and enhancing their writing in local contexts [46]. As Malekzadeh and Najmi also point out, teachers need to understand students' learning styles and choose appropriate technological tools through flexible adaption [45]. For example, for some students, using mobile devices and creating a collaborative learning environment may improve their efficacy in understanding required writing content. Other students may prefer receiving podcasts related to materials and having their own space for writing through mobile devices. In either scenario, this requires teachers' constant efforts to prioritize their student writers' needs.

\section{$5 \quad$ Conclusion and Implications}

With improvements in the technology, batteries, and processors of mobile devices, MALL is an area that cannot be ignored in this digitalized world. However, writing, a crucial literacy for students, has not been combined with MALL as much as other 
literacies (e.g., learning vocabulary). A meaning-making-based approach to mobileassisted writing instruction seems quite promising because this combination aligns with expectations of effective writing and incorporates the advantages of MALL (e.g., portability and engaging platform for learning). Accordingly, it merits empirical studies conducted in the context of higher education.

The implications of this discussion paper include the following. While mobile learning is convenient for its portability and freedom from geographic constraints, students may be distracted by games or other entertaining programs [47]. Predictably, some students may be distracted in the process of learning (e.g., responding to friends' messages on social media). This means that mobile users may need to develop the habit of focusing on learning as they do with in-class learning to improve their learning efficiency. Additionally, mobile application designers and instructors should work with each other and integrate meaning-making knowledge with multimedia features (e.g., voice recording, camera, graphic tools), thereby enhancing students' learning inside and outside the classroom, including speaking and listening. Most importantly, more research along this line is urgently needed, especially with a more critical and analytical perspective, to supplement and strengthen the findings of the present study.

\section{References}

[1] S. Papadakis, J. Vaiopoulou, M. Kalogiannakis, and D. Stamovlasis, "Developing and Exploring an Evaluation Tool for Educational Apps (ETEA) Targeting Kindergarten Children," Sustainability, vol. 12, no. 10, p. 4201, May 2020. https://doi.org/10.3390 /su12104201

[2] S. Papadakis, "Tools for evaluating educational apps for young children: a systematic review of the literature," Interactive Technology and Smart Education, vol. ahead-of-print, no. ahead-of-print, Dec. 2020. https://doi.org/10.1108/itse-08-2020-0127

[3] S. Papadakis, "Apps to Promote Computational Thinking Concepts and Coding Skills in Children of Preschool and Pre-Primary School Age," In S. Papadakis \& M. Kalogiannakis (Eds.), Advances in educational technologies and instructional design (AETID). Mobile learning applications in early childhood education (p. 101-121). Information Science Reference/IGI Global. https://doi.org/10.4018/978-1-7998-1486-3.ch006

[4] M. Drolia, E. Sifaki, S. Papadakis, and M. Kalogiannakis, "An Overview of Mobile Learning for Refugee Students: Juxtaposing Refugee Needs with Mobile Applications' Characteristics," Challenges, vol. 11, no. 2, p. 31, Dec. 2020. https://doi.org/10.3390 /challe11020031

[5] A. Kukulska-Hulme and L. Shield, "An overview of mobile assisted language learning: From content delivery to supported collaboration and interaction," ReCALL, vol. 20, no. 3, pp. 271-289, Aug. 2008. https://doi.org/10.1017/s0958344008000335

[6] Z. Li and V. Hegelheimer, "Mobile-assisted grammar exercises: Effects on self-editing in L2 writing," Language Learning \& Technology, vol.17, no. 3, pp.135-156, Oct. 2013.

[7] Z. Xu, M. Banerjee, G. Ramirez, G. Zhu, and K. Wijekumar, "The effectiveness of educational technology applications on adult English language learners' writing quality: a metaanalysis," Computer Assisted Language Learning, vol. 32, no. 1-2, pp. 132-162, Dec. 2018. https://doi.org/10.1017/s0958344008000335 
[8] P. Gibbons, Scaffolding language, scaffolding learning. Portsmouth, NH: Heinemann, 2002.

[9] R. Harman, Transforming normative discourses of schooling: Critical systemic functional linguistics praxis. New York: Springer, 2018.

[10] M. J. Schleppegrell, "The knowledge base for language teaching: What is the English to be taught as content?” Language Teaching Research, vol. 24, no. 1, pp. 17-27, Jul. 2018. https://doi.org/10.1177/1362168818777519

[11] I. H. Al-Naibi, M. Al-Jabri, and I. Al-Kalbani, "Promoting students' paragraph writing using EDMODO: An action research," Turkish Online Journal of Educational Technology, vol. 17, no. 1, 130-143, Jan. 2018.

[12] R. Shadiev, W.-Y. Hwang, and Y.-M. Huang, "Review of research on mobile language learning in authentic environments," Computer Assisted Language Learning, vol. 30, no. 3-4, pp. 284-303, Apr. 2017. https://doi.org/10.1080/09588221.2017.1308383

[13] X. Zhang, "Connecting OER with mandatory textbooks in an EFL classroom: A language theory-based material adoption," The International Review of Research in Open and Distributed Learning, vol. 19, no. 2, pp. 89-110, May 2018. https://doi.org/10.19173/irrodl. v19i2.3479

[14] M. A. K. Halliday, An Introduction to Functional Grammar. London: Edward Arnold, 2014.

[15] D. Rose and J.R. Martin, learning to write, reading to learn: Genre, knowledge and pedagogy in the Sydney School. London: Equinox, 2012.

[16] S. Pessoa, "How SFL and explicit language instruction can enhance the teaching of argumentation in the disciplines," Journal of Second Language Writing, vol. 36, pp. 77-78, Jun. 2017. https://doi.org/10.1016/j.jslw.2017.05.004

[17] M. E. Brisk, Engaging Students in Academic Literacies: Genre-based Pedagogy for K-5 Classrooms. New York, NY: Routledge, 2014. https://doi.org/10.4324/9781317816164

[18] A. Nagao, "The SFL genre-based approach to writing in EFL contexts," Asian-Pacific Journal of Second and Foreign Language Education, vol.4, no.1, May, 2019. https://doi.org/10.1186/s40862-019-0069-3

[19] S. Yasuda, "Exploring changes in FL writers' meaning-making choices in summary writing: A systemic functional approach," Journal of Second Language Writing, vol. 27, pp. 105-121, Mar. 2015. https://doi.org/10.1016/j.jslw.2014.09.008

[20] J. Moore, M. Schleppegrell, and A. S. Palincsar, "Discovering disciplinary linguistic knowledge with English learners and their teachers: Applying systemic functional linguistics concepts through design-based research," TESOL Quarterly, vol. 52, no. 4, pp. 10221049, Aug. 2018. https://doi.org/10.1002/tesq.472

[21] A. Andujar, "Benefits of mobile instant messaging to develop ESL writing," System, vol. 62, pp. 63-76, Nov. 2016. https://doi.org/10.1016/j.system.2016.07.004

[22] A. Kukulska-Hulme and O. Viberg, "Mobile collaborative language learning: State of the art," British Journal of Educational Technology, vol. 49, no. 2, pp. 207-218, Sep. 2017. https://doi.org/10.1111/bjet.12580

[23] L. Sessions, M. O. Kang, and S. Womack, “The Neglected 'R': Improving writing instruction through iPad apps," TechTrends, vol. 60, no. 3, pp. 218-225, Feb. 2016. https://doi.org/10.1007/s11528-016-0041-8

[24] M. N. Kayaoğlu and Ş. Erbay Çetinkaya, "Using what students have at their fingertips: Utilising mobile phones for circular writing," The Qualitative Report, vol. 23, no. 12, 3098-3115, Dec. 2018. 
[25] J. Harris, P. Mishra, and M. Koehler, "Teachers' technological pedagogical content knowledge and learning activity types," Journal of Research on Technology in Education, vol. 41, no. 4, pp. 393 - 416, Jun. 2009. https://doi.org/10.1080/15391523.2009.10782536

[26] H. S. R. Noriega, "Mobile learning to improve writing in ESL teaching," TEFLIN Journal, vol. 27, no. 2, p. 182-202, Oct. 2016. https://doi.org/10.15639/teflinjournal.v27i1/182-202

[27] S. Borg, Teacher cognition and language education. London: Continuum, 2006.

[28] P. M. Sadler, G. Sonnert, H. P. Coyle, N. Cook-Smith, and J. L. Miller, "The influence of teachers' knowledge on student learning in middle school physical science classrooms," American Educational Research Journal, vol. 50, no. 5, pp. 1020-1049, Oct. 2013. https://doi.org/10.3102/0002831213477680

[29] B. Mei, G. T. L. Brown, and T. Teo, "Toward an understanding of preservice English as a foreign language teachers' acceptance of computer-assisted language learning 2.0 in the People's Republic of China," Journal of Educational Computing Research, vol. 56, no. 1, pp. 74-104, Mar. 2017. https://doi.org/10.1177/0735633117700144

[30] C. Vicentini and L. C. deOliveira, "Using technology tools in writing instruction," NYS TESOL Journal, vol. 5, no. 2, pp. 45-51, July, 2018.

[31] A. Gordillo, S. López-Pernas, and E. Barra, "Effectiveness of MOOCs for teachers in safe ICT use training," Comunicar, vol. 27, no. 61, pp. 103 - 112, Oct. 2019. https://doi.org/10. 3916/c61-2019-09

[32] L. M. Ungerer, "Digital curation as a core competency in current learning and literacy: A Higher education perspective," The International Review of Research in Open and Distributed Learning, vol. 17, no. 5, Sep. 2016. https://doi.org/10.19173/irrodl.v17i5.2566

[33] T. S. C. Farrell, "Tailoring reflection to individual needs: A TESOL case study," Journal of Education for Teaching, vol. 27, no. 1, pp. 23-38, Apr. 2001. https://doi.org/10.1080/02607470120042528

[34] M. C. O'Sullivan, “Action research and the transfer of reflective approaches to in-service education and training (INSET) for unqualified and underqualified primary teachers in Namibia," Teaching and Teacher Education, vol. 18, no. 5, pp. 523-539, Jul. 2002. https://doi.org/10.1016/s0742-051x(02)00014-8

[35] W. Sugar, F. Crawley and B. Fine, "Examining teachers' decisions to adopt new technology,” Educational Technology and Society, vol 7. no. 4, pp. 201-213, Oct. 2004.

[36] B. R. Beatty, "Teachers leading their own professional growth: Self-directed reflection and collaboration and changes in perception of self and work in secondary school teachers," Journal of In-Service Education, vol. 26, no. 1, pp. 73-97, Mar. 2000. https://doi.org/10. $\underline{1080 / 13674580000200102}$

[37] P. Chappell and S. Moore, "Novice teachers and linguistics: Foregrounding the functional," TESOL Quarterly, vol. 46, no. 3, pp. 589-598, Aug. 2012. https://doi.org/10.1002/tesq.44

[38] M. Gebhard, "Teacher Education in Changing Times: A Systemic Functional Linguistics (SFL) Perspective,” TESOL Quarterly, vol. 44, no. 4, pp. 797-803, Dec. 2010. https://doi. org/10.5054/tq.2010.237335

[39] M. Macken-Horarik, "Why school English needs a 'Good Enough' grammatics (and not more grammar),” Changing English, vol. 19, no. 2, pp. 179-194, Jun. 2012. https://doi.org/ $\underline{10.1080 / 1358684 x .2012 .680760}$

[40] G. Luque Agulló and N. Martos Vallejo, "Mobile learning in the foreign language classroom,” Huarte de San Juan. Filología y Didáctica de la Lengua, 15, pp.79-10, 2015.

[41] S. A. Sharma and M. E. Deschaine, "Digital curation: A framework to enhance adolescent and adult literacy initiatives," Journal of Adolescent \& Adult Literacy, vol. 60, no. 1, pp. 71-78, Apr. 2016. https://doi.org/10.1002/jaal.523 
[42] Z. Aguirre-Muñoz, J. E. Park, A. Amabisca, C. K. Boscardin, "Developing teacher capacity for serving ELLs' writing instructional needs: A case for systemic functional linguistics," Bilingual Research Journal, vol. 31, no. 1-2, 295-322, Mar, 2009. https://doi.org/10.1080/15235880802640755

[43] K. Accurso, M. Gebhard, C. Selden, "Supporting L2 elementary science writing with SFL in an age of school reform," In Second Language Writing in Elementary Classrooms: Instructional Issues, Content-area Writing and Teacher Education, L. De Oliveira and T. Silva, Eds. London, UK: Palgrave Macmillan, 2016, pp. 126-150. https://doi.org/10.1057/9781137530981_8

[44] T.-C. Hsu, "Learning English with augmented reality: Do learning styles matter?" Computers \& Education, vol. 106, pp. 137-149, Mar. 2017. https://doi.org/10.1016 lj.compedu.2016.12.007

[45] R. Malekzadeh and K. Najmi, "The effect of mobile-assisted language learning (MALL) on guided writing skill of Iranian upper-intermediate EFL learners," Journal of Applied Linguistics and Language Research, vol. 2, no. 4, pp. 42-52, 2015.

[46] M. L. Louws, J. A. Meirink, K. van Veen, J. H. van Driel, "Teachers' self-directed learning and teaching experience: What, how, and why teachers want to learn," Teaching and Teacher education, vol. 66, pp. 171-183, Aug, 2017. https://doi.org/10.1016 /j.tate.2017.04.004

[47] S. Smith and S. Wang, "Reading and grammar learning through mobile phones," Language Learning \& Technology, vol. 17, no. 3, pp. 117-134, Oct, 2013.

\section{$7 \quad$ Author}

Xiaodong Zhang is an associate professor at School of English and International Studies in Beijing Foreign Studies University, China. His work has appeared in several international journals. His research interests include teacher education, second language learning and educational technology.

Article submitted 2021-01-26. Resubmitted 2021-03-23. Final acceptance 2021-03-23. Final version published as submitted by the authors. 


\section{Appendix}

1. An introduction of SFL

https://www.youtube.com/watch?v=RWznZoq43xQ (a 21-minute introduction of SFL, including what is field, tenor and mode)

2. Textual meaning and linguistic resources

http://www.funenglishgames.com/grammargames/conjunction.html (an online game for practicing textual meaning and conjunction words)

https://writesite.elearn.usyd.edu.au/m3/m3u $/ \mathrm{m} 3 \mathrm{u} 5 \mathrm{~s} 3 / \mathrm{m} 3 \mathrm{u} 5 \mathrm{~s} 3$ _ $1 . \mathrm{htm}$ (online learning for thematic progression in writing)

3. Interpersonal meaning and linguistic resources

https://writesite.elearn.usyd.edu.au/m2/m2u4/m2u4s $4 / \mathrm{m} 2 \mathrm{u} 4 \mathrm{~s} 4$ _ 1 1.htm (a link for understanding evaluative verbs as one part of interpersonal meaning)

4. Ideational meaning and linguistic resources

http://blogs.ubc.ca/lled3602015/files/2015/08/Schleppegrell_Linguistic_Features. pdf (a link for understanding the choice of processes or participants at the ideational level in academic writing). 